\title{
Demência Frontotemporal e Teoria da Mente
}

\section{Leonardo Caixeta}

Professor Associado de Neuropsiquiatria da Universidade Federal de Goiás (UFG). Coordenador do Ambulatório de demências do Hospital das Clínicas da UFG, Goiânia-GO, Brasil.

Para podermos inferir a respeito dos estados mentais dos outros se faz mister que estejamos equipados com uma habilidade que nos permita desenvolver uma medida daquilo que eles pensam e desejam. Esta capacidade foi denominada Teoria da Mente (ToM). Um indivíduo tem uma Teoria da Mente se ele imputa estados mentais para si mesmo e para os outros; um sistema de inferências desta natureza é apropriadamente visto como uma 'teoria' porque tais estados não são diretamente observáveis e o sistema pode ser usado para fazer previsóes sobre o comportamento dos outros ${ }^{1}$. Este constructo permite capturarmos uma dimensão da consciência que é especialmente relevante para as funçóes instrumentais e sociais da vida diária e que, em última análise, foi a principal habilidade a favorecer a manutenção e superioridade da espécie humana perante os outros seres vivos ${ }^{1}$. O conceito de ToM originou-se da primatologia para depois ganhar espaço dentro da psicologia cognitiva e mais recentemente tem sido exportado para outros campos do saber e incorporado pelas ciências médicas com a pretensão de explicar determinadas alteraçóes cognitivas e de comportamento que constituem o cerne de distúrbios como o autismo infantil, a esquizofrenia e psicoses afins, além de doenças degenerativas como a demência frontotemporal ${ }^{2}$. Esta incorporação trouxe a necessidade de desenhar metodologias que possam mensurar e definir a ToM em termos neurobiológicos. Surge, de forma inescapável, a questão: como poderíamos operacionalizar o conceito de "atribuição de intençóes” (ou Teoria da Mente), de tal maneira que ele pudesse ser testado?

Neste contexto, o artigo "Frontotemporal dementia deficit in Theory of Mind assessed with Happés Test" de Daniel Serrani ${ }^{3}$, publicado neste número da Revista Neurociências, aborda de forma elegante e operacional o conceito de ToM, testando-o em pacientes portadores de demência frontotemporal (DFT) em comparação com pacientes portadores de doença de Alzheimer. Com isto, Serrani abrange dois dos temas mais estimulantes dentro do cenário das neurociências atuais - a consciência e os lobos frontais - ao enfocar a maneira como ToM e DFT se interpenetram. A DFT constitui doença primariamente degenerativa do SNC que apresenta caracteristicamente alteraçôes neuropatológicas focais nos lobos frontais associadas a prejuízos do comportamento social e empáti$\mathrm{co}^{4}$. A DFT representa, portanto, um ótimo modelo para o estudo de associaçóes clínico-patológicas no âmbito da psiquiatria, uma área que carece de tais correlaçóes, uma vez que historicamente sempre existiu o desafio e a dificuldade de se associar determinados comportamentos a substratos neurobiológicos específicos. Dados o interesse e a necessidade no amadurecimento do diálogo entre neuropatologia e psiquiatria, bem como o crescente enfoque nas regióes pré-frontais para o esclarecimento da patogênese dos transtornos psiquiátricos, as síndromes cerebrais orgânicas causadas por lesões frontais e que cursam com alteraçóes cognitivas e de comportamento se revelam especialmente importantes para o entendimento de aspectos ainda obscuros da mente humana. Mais especificamente, o estudo de determinados sintomas cognitivos ou comportamentais da DFT pode trazer contribuições para o seu entendimento também nas doenças psiquiátricas uma vez que muitos destes sintomas são compartilhados por ambas as condiçóes. Assim, quando se estuda, por exemplo, as alterações da ToM na DFT e as relacionamos com alteraçóes neuroanatômicas específicas (como no caso do artigo de Serrani), poderemos com isto ampliar o conhecimento de aspectos neurobiológicos destes mesmos sintomas (da ToM) em transtornos como a esquizofrenia e o autismo infantil.

Como o suporte empírico para as teses que associam a ToM a uma topografia neuroanatômica específica ainda é escasso, o trabalho de Serrani se torna muito 
oportuno. O artigo de Serrani vem se somar aos achados de outros estudos que associaram a ToM a alteraçóes préfrontais, especificamente em casos de DFT, como nos primeiros trabalhos sobre este tópico conduzidos por nosso grupo em 1997 e 20015,6. As regiōes pré-frontais são as áreas do SNC mais recentes do ponto de vista filo e ontogenético nos mamíferos e estão intimamente relacionadas a muitos dos atributos que distinguem o Homo sapiens sapiens dos demais seres vivos: criatividade, auto-controle, pensamento e interação social. Estudos de neuroimagem funcional realizados no momento em que indivíduos normais eram testados em tarefas relacionadas à ToM demonstraram que o córtex frontal (sobretudo o córtex pré-frontal meso-orbitário) parece ser a região mais relacionada a esta habilidade cognitiva ${ }^{1}$.

Serrani administrou testes neuropsicológicos, de função executiva, a escala de depressão de Yesavage e um paradigma de ToM utilizando o Teste de Histórias Estranhas de Happé para avaliar a capacidade de 20 pacientes com DFT e 20 com doença de Alzheimer em inferir os estados mentais e interpretar afirmaçóes não literais (metafóricas). Como demonstrado em outros estudos ${ }^{7}$, apesar do grupo com DFT exibir pior desempenho no Teste de Histórias Estranhas de Happé, não se observou correlação significativa deste prejuízo com medidas de disfunção executiva, indicando que o déficit em subáreas da ToM não parece ocorrer em consequência da disfunção executiva experimentada por tais indivíduos. $\mathrm{O}$ achado de neuroimagem funcional (SPECT cerebral) de hipoperfusão ventromedial associado às dificuldades da ToM ajuda a corroborar a impressáo de que náo se trata de um problema secundário às disfunçóes executivas, uma vez que estas últimas se associam à hipoperfusão dorsolateral. É necessário muito cuidado, porém, para não incorrer na equivalência equivocada entre atribuição de intenções e ToM, ou entre bom desempenho nas provas de crenças falsas e ToM, uma vez que o construto é muito mais complexo e se estaria avaliando apenas um de seus aspectos.
A incorporação do constructo ToM pelas neurociências trouxe interessantes contribuiçóes para a compreensão de como determinadas alteraçóes cognitivas e de comportamento que constituem o núcleo fenomenológico de entidades nosológicas como o autismo infantil e a esquizofrenia poderiam eventualmente ser entendidas como manifestaçôes variadas de prejuízos nesta habilidade cognitiva. Foi assim que, por exemplo, passou-se a compreender a dificuldade de interação social dos autistas como um fenômeno secundário ao prejuízo da ToM. Foi assim também que se interpretou os delírios paranóides como conseqüência da dificuldade experimentada pelos pacientes em fazerem leituras mentais corretas dos outros (ou seja, dificuldade na ToM), imputando estados mentais falsos e descontextualizados (por exemplo, acreditar que a alguém que os está observando por um motivo banal constitui na verdade uma ameaça).

\section{REFERÊNCIAS}

1.Caixeta M, Caixeta L. Teoria da Mente - aspectos psicológicos, neurológicos, neuropsicológicos e psiquiátricos. Campinas: Editora Átomo, 2005, 138p.

2.Caixeta L, Nitrini R. Teoria da mente: uma revisão com enfoque na sua incorporação pela psicologia médica. Psicologia: Reflexão e Crítica 2002;15:105-112. http://dx.doi.org/10.1590/S0102-79722002000100012

3.Serrani D. Frontotemporal dementia deficit in Theory of Mind assessed with Happé's Test. Rev Neurocienc 2011;19:413-22.

4.Caixeta L, Nitrini R. Subtipos clínicos da demência frontotemporal. Arquivos de Neuropsiquiatria 2001; 59(3-A):577-81.

http://dx.doi.org/10.1590/S0004-282X2001000400017

5.Caixeta L. Neurobiologia e fenomenologia dos distúrbios da auto-consciência na Demência Frontotemporal e na Doença de Alzheimer (Tese). São Paulo: USP, 2000.

6.Caixeta L, Simone A, Nitrini R. Mind Theory and frontotemporal dementia: a study of 5 cases. The Journal of Neuropsychiatry and Clinical Neurosciences 1997;9(4):690.

7.Aboulafia-Brakha T, Christe B, Martory MD, Annoni JM. Theory of mind tasks and executive functions: a systematic review of group studies in neurology. J Neuropsychol 2011;5(Pt 1):39-55.

http://dx.doi.org/10.1348/174866410X533660 